\title{
Care Robot Orientation: What, Who and How? Potential Users' Perceptions
}

\author{
Rose-Marie Johansson-Pajala' (1) - Kirsten Thommes ${ }^{2}$. Julia A. Hoppe ${ }^{2} \cdot$ Outi Tuisku $^{3} \cdot$ Lea Hennala $^{3}$. \\ Satu Pekkarinen ${ }^{3} \cdot$ Helinä Melkas ${ }^{3} \cdot$ Christine Gustafsson $^{1}$
}

Accepted: 2 January 2020 / Published online: 21 January 2020

(c) The Author(s) 2020

\begin{abstract}
Exploring the specific field of care robot orientation generates many questions regarding the meaning, content and how it should be conducted. The issue is important due to the general digitalisation and implementation of welfare technology and care robots. The aim of the study was to explore perceptions of care robot orientation from the potential users' perspective. Data were collected by focus group interviews in Finland, Germany and Sweden. In all three countries, potential user groups were represented: older adults, relatives, professional caregivers and care service managers. A qualitative descriptive method was used for analysing data. The data revealed three aspects of care robot orientation: (1) What care robot orientation is, (2) Who needs it and by Whom it should be given and (3) How it should be performed. The need for care robot orientation is general in society. In the absence of knowledge about care robots, it is nearly impossible to know what to ask for or actually seek information about. Therefore, care robot orientation must be founded on agile implementation planning for care robots, with a firm basis in trustworthy knowledge and information and respecting individuals' wishes. This also gives rise to an ethical challenge when care robots are offered to people having reduced decision-making ability (dementia, cognitive impairment), along with the issue of who then should make the decision. The mapping of the What, Who/Whom and How aspects of care robot orientation offers a foundation for the creation of orientation models, which might facilitate structured and goal-oriented care robot orientation strategies.
\end{abstract}

Keywords Care robots · Focus group · Older adults · Orientation · Qualitative research · Welfare technology

\section{Introduction}

A rapidly growing number of older adults addresses a demographic challenge [1]. As a result of aging and increased life expectancy, the relative population of older adults in Western Europe will increase [2]. One estimation is that in 2050 there will be 164 million people over the age of 65 in Europe [1], and globally the number of people older than 60 years is expected to be higher than the number of people younger than 15 years [3]. This brings an increased need for health

Rose-Marie Johansson-Pajala

rose-marie.johansson-pajala@mdh.se

1 School of Health, Care and Social Welfare, Mälardalen University, P.O 325, 63105 Eskilstuna, Sweden

2 Paderborn University, Paderborn, Germany

3 Lappeenranta-Lahti University of Technology LUT, Lahti, Finland care services, but the number of people available to provide and finance these services is decreasing [4]. Welfare technology, referring to all technology that improves the lives of those in need, is considered to be one solution to meet these challenges [5]. Welfare technology is introduced into private homes, offering social stimuli, services and entertainment [6], which is expected to facilitate a prolonged independent life for older adults [7]. This paper takes a specific welfare technology focus on care robots, a sub-category of service robots that are mainly used in welfare services [8]. Personal care robots are defined as robotics that improve the quality of life of humans, on a non-medical basis $[9,10]$. More specifically, we refer to care robots as machines that operate partly or fully autonomously with the aim of supporting potential users, older adults and relatives as well as professional caregivers, in providing physical, cognitive or emotional support $[11,12]$. In order to understand how care robots can be used in care, we need to understand the orientation process of the stakeholders involved. We perceive orientation 
to be the continuous co-creative process of introduction to technology use and its familiarisation, including learning of multi-faceted knowledge and skills for effective use, here in relation to care robots in elder care. The present paper explores care robot orientation (hereafter CRO) from the perspective of potential users in Northern Europe, represented by Finland, Germany and Sweden.

\section{Background}

Older adults may suffer from frailty, meaning concurrent loss of several capabilities, involving disability, dependency, falls, need for long-term care and mortality [13]. These are conditions that require assistance in daily living. Informal caregivers provide an essential part of the care, however, they cannot be expected to take full responsibility. Welfare technology, such as care robots, has been suggested as a way of bridging the widening gap between the demands and supply of health care services [14]. Welfare technology, including care robots, used by older adults as well as relatives and professional caregivers, can help people to live a healthy life with retained integrity, contribute to efficiency in elder care services and meet individuals' needs for living independently [15]. In some care situations, it may also be less stigmatising for the older adults to receive care from robots instead of humans, for instance regarding hygiene [16] or when they refuse care [17]. The current older generation also has more money to spend compared to previous generations and can thereby afford to invest in products that can improve their lives [18] and enable them to age in place.

\subsection{Care Robots in Elder Care}

When focusing on elder care, it becomes apparent that a gigantic technology shift must take place in order to meet the societal demographic challenges [2,3]. Care robots are receiving growing attention in elder care since their use has proven to have a positive impact, not only on older adults but also for those who work with them, including professional caregivers and relatives [19]. In a recent project on older adults' requirements with respect to robotics, García-Soler et al. find a high number of demands. Older adults and caregivers expect that care robots would support daily activities as well as provide cognitive and social support. Other requirements are related to monitoring, privacy and safety. Suitability to the environment and customisation and adaption are also prioritised areas [20]. However, the description of frail older adults having a general need for various robotic assistance, due to societal changes, has been criticised. Frennert and Östlund argue that this conceptualisation seems to be plagued with stereotypical perceptions and that the prevailing view of older adults needs to be re-evaluated [21].
Also, there exists a wide range of robots, and requirements might depend on the specific robot at hand.

Up to now, the different types of care robots used in elder care mainly have provided support regarding assistance in daily tasks, monitoring behaviours and health and providing companionship [22, 23]. Some examples are Care-O-bot [24], Robot-Era robots [25], Zora [26], JustoCat [27] and PARO [28], amongst others. However, it has been predicted that the health care robotics industry will integrate robotics into health care at an alarming rate and will reach a value of 50 billion US dollars by 2025 [29]. Still, the acceptance of care robots has so far been rather poor and the market largely untapped, despite the potential benefits they are meant to provide [18]. Besides the technological limitations of current prototypes, ethical, social, organisational and market-driven barriers are identified [17]. A systematic review identified 107 robots designed for older adults. Only six of them were commercially available; the rest were either in a conceptual or development phase [30]. This review was conducted some years ago, but a low level of dissemination still seems to be prevailing. One contributing factor for the lack of care robot uptake may, according to Broadbent et al. [31], be that the designers have not properly researched the needs and desires of the potential users in elder care. Another factor might be the regulations and high standards applying to designers and manufacturers, when developing care robots intended to work in close interaction with humans. Guaranteed safety independently from users' experience and actions is required, which may pose a problem for small and medium sized enterprises with limited resources and experience [32, 33].

\subsection{Acceptance of Care Robots}

Acceptance of care robots is a delicate issue, and many are opposed to their use in elder care [34,35]. One must be aware that the existing attitudes are embedded in a personal, social and physical context [36]. Questions on care robot acceptance in elder care have attracted special interest since the subject is challenging due to ethical as well as social issues [37, 38]. Perceptions about the use of care robots are influenced by how one views the traditional boundaries of the ethical landscape in the care of older adults [39]. Thus, the ethical aspects related to the use of care robots must be carefully examined and respected. Sharkey and Sharkey [40] described the main ethical concerns, when it comes to the use of robots in elder care, in terms of reduced human contact, loss of privacy, deception and infantilisation, loss of control, loss of personal liberty and questions about responsibility if something goes wrong with the robot.

Acceptance of care robots depends on many factors. Among older adults, their relatives and professional caregivers, individual factors that affect the adoption include 
age, needs, gender and experiences with technology/robots. Cognitive ability and education, culture, roles, anxiety and attitudes towards robots are also influencing factors. Additionally, adoption is affected by robot factors, such as appearance, humanness, facial dimensions and expressions, size and adaptability [17]. Other factors for acceptance, suggested by Young et al. [41], are safety, accessibility, usability, practical benefits, fun, social pressure, status gains and the social intelligence of the robot. Due to the wide variety of care robots, their tasks and appearances, more research on factors of acceptance on different types is needed, especially due to the rapid development of robot technology. For instance, zoomorphic robots (such as JustoCat), may stimulate users and connect with prior experiences, by evoking happy caring emotions, previously generated when interacting with pets [42]. On the other hand, Pfadenhauer and Dukat [43] found that a robot's appearance and its deployment were independent, as through these humans establish how (and if) a technology will be used and what it means to them.

Some of the work done on perceptions towards care robots tends to describe negative attitudes. Regarding the perceptions of the EU population on robots in geriatric care, over 30 percent of the respondents considered the idea of robots in geriatric care to be very unpleasant [44]. Associations have also been made between attitudes to robots in elder care and age, in particular that older adults are more negative than younger people [22]. Still, some research suggests that the attitudes of older adults are more often positive than negative [31, 45-47]. In fact, negative ageist stereotyping is a cultural and societal issue, which can reduce the acceptance of robots [48].

The potential users of care robots in elder care also include the caregivers. Thus, their orientation process need to be understood, especially considering that professional caregivers' resistance to implementing welfare technology in general, has been recognised. The resistance is related to organisational, cultural and technological as well as ethical issues [49]. It has even been suggested that professional caregivers have more concerns about robots than older adults [50] and the population in general [51]. Among the occupational groups, assistant nurses have been shown to be most reluctant regarding care robot use, while head nurses and other managers have the most positive view [51]. One example of professional caregivers' concerns, in relation to introducing care robots in home care, is described as thoughts of how useful the robot is. The expectations of their colleagues as well as their own perceptions on their capacity to learn to use the robot also affected the adoption [52]. Among nurses, representing the group of professional caregivers, one likely explanation might be that technological integration and the exponential growth of technology is currently underrepresented in nursing frameworks [53].
The literature has not really addressed how professionals will assist vulnerable older adults in the selection and use of care robots [29]. Caregiving and care robots also still represent a small-scale topic of discussion, which is mainly narrowed to robots in medical health care, rather than elder care [54]. However, predictions suggest that robotics will alter the scope of practice in the caregiving profession, and planning is required to lead the integration of care robots into the domain of nursing [53]. Relatives have been found to be more negative towards care robots than older adults $[31,49]$. However, their views, of course, differ depending on the specific care robot involved. When, for example, the relatives' acceptance of the use of PARO [28] was investigated, positive perceptions were expressed [55].

\subsection{Attitudes and Orientation Among Potential Users}

The attitude towards care robots in elder care is an important aspect in determining whether care robots will be accepted by the potential users or not. If the introduction of care robots in elder care is to be successful, then care robots need to be accepted by the population in general and older adults in particular [17]. However, it has been found that public knowledge about robots seems vague, as the public tends to lack information on how care robots can be used in elder care [35]. Previous studies report that when participants did not have experiences with the robot in question, more negative attitudes were prevalent $[56,57]$. For that reason, the public need more information on how care robots can be used, and the concrete benefits need to be communicated and demonstrated [35, 36]. Also, appropriate education for familiarising people with robots can reduce hostility [22]. Heerink et al. find that the intention to use a robot is impacted by other acceptance factors and can be predicted by the user's attitude and how much they perceive the robots to be useful [58].

For care robots to be used and accepted, it is imperative that the potential users be involved in the conceptualisation, development and testing of new products to ensure appropriateness $[34,59]$. Strategies need to be developed addressing the needs and fears of all stakeholders involved in the normalisation process of care robot use. We need to understand how orientation in the field should be delivered to facilitate the acceptance and normalisation of care robots in elder care for exploiting the benefits such as increased quality in elder care and improved independence in everyday life. The latter is considered to be of extra value in Western culture [60].

To change attitudes about care robots is considered essential, if the use of this type of welfare technology is to be accepted and introduced in elder care. According to Ienca et al. [61], knowledge dissemination is a key factor to favour interaction and information sharing among the relevant 
stakeholders who are involved in the care and management of care robots. One factor referring to the general acceptance is orientation, in this case orientation to care robots. At best, orientation implies provision of knowledge, skill and competence for the benefit of making informed assumptions and decisions. Accordingly, orientation is here perceived to be the continuous co-creative process of introduction to technology use and its familiarisation, including learning of multi-faceted knowledge and skills for effective use.

\subsection{Rationale and Aim}

Exploring the field of welfare technology and specific CRO generates many questions to answer regarding the meaning, content and how it should be conducted. The issue is important because of the rapid digitalisation and development of health and welfare technology. There are also expectations that robots and welfare technology in general should solve the demographic challenge the global society is facing. A deeper knowledge on the orientation process of the involved stakeholders is needed to utilise the advantages of robot technologies on the one hand while at the same time considering and addressing stakeholders' obstacles when robot technology is introduced. As a part of identifying and developing best practices for orientation into care robot use in welfare services for older adults, the objective of the present study was to explore perceptions of CRO from the potential users' perspective. To gain a comprehensive overview, we include all four direct user groups: older adults, relatives, professional caregivers and care service managers.

\section{Methods}

The study has a qualitative descriptive design according to Sandelowski [62]. The focus was to understand the potential users' perspective of CRO. Focus group discussions were conducted in Finland, Germany and Sweden.

\subsection{Recruitment}

Purposeful sampling was used to recruit the four different groups: older adults, relatives, professional caregivers and care service managers $[62,63]$. The four groups were chosen to represent those who are primarily involved in providing or receiving care and thereby potential users of care robots. Recruitment was done through verbal and written requests to retirement organisations, family associations, professional caregivers and care service managers in municipal elder care. Inclusion criteria were that the informants should have an interest in the area. Variations in gender were strived for, as well as in occupations in the group with professional caregivers. The recruitment was performed independently for the different groups. The older adults lived in their own housing and were not associated to either the professional caregivers or the relatives. The professional caregivers came from different settings and so did the care service managers, although some might have been somewhat acquainted due to working in the same area of care.

The informants have their origin in three countries with some differences in welfare systems. In Finland and Sweden, the elder care services are the public sector's responsibility, mainly the municipalities, while in Germany, elder care is primarily funded by insurances.

\subsection{Focus Groups}

A detailed interview guide was developed by the research team [64] to ensure consistency across the different groups (Table 1). Prior to the start of the study, pilot-discussions were performed in each country. The focus groups were homogenous in the sense that each group of informants met separately. Four focus group discussions, one with each of the represented groups, were conducted in Finland and in Sweden. In Germany, two focus groups were conducted with older adults, resulting in a total of five focus group discussions. Altogether, 71 informants participated in a total of 13 focus groups, with 4-7 informants in each group, consisting

Table 1 Interview guide

\begin{tabular}{ll}
\hline Introduction question & Brainstorm on the use and need for care robots within the field of elder care \\
Transition question & Thoughts about the use/introduction of care robots in elder care. Should we have care robots in elder care? \\
Key questions & Display of a video clip and pictures \\
& Reflections on the video clip and pictures; benefits and disadvantages from different perspectives \\
Further questions: \\
How would you feel about being cared for/assisted by a care robot when you get old and need help? \\
Do we, in general, need to know more about care robots? What? Why? How? By whom? \\
If you would like to learn more about care robots, how would you do this? \\
How should the use of care robots be introduced in elder care, and what training is required? \\
How much do you think this kind of technology costs? \\
Reflection on what was said during the discussion: Does anything need to be added? The assistant mod- \\
erator is invited to reflect/ask additional questions \\
\hline
\end{tabular}


of older adults living in their own housing (24), relatives of care-dependent older adults (16), professional caregivers in assisted living facilities or home care (16) and care service managers in assisted living facilities (15) (Table 2).

Prior to the focus group discussions, the informants completed a questionnaire with their background data and signed an informed consent form. Two to three researchers were present during the focus groups, one acting as a moderator and the other(s) as assistant moderator. The role of the moderator was to direct the discussion and make sure that all informants had their say. The assistant moderator took comprehensive notes and was invited into the discussion at the end of the interview. As the informants had limited experience of care robots, they were shown a 3-min long video clip of three examples. The first was Care-O-bot [24], a mobile robot assistant for supporting humans in their daily life. The second was JustoCat [27], a social robot used for improving life for people with dementia, and specifically adapted for health care environments. The last example was Zora [65], a humanoid robot designed to assist caregivers, for example by supporting and promoting activity in older adults. In addition to the video clip, pictures were displayed that exemplified other types of care robots, used for social, physical and mental stimulation as well as communication. The focus groups were conducted in the informants' native language and lasted for 60-140 min. All discussions were audio recorded and then transcribed verbatim and processed as texts.

Table 2 Demographic data

\begin{tabular}{|c|c|c|c|c|}
\hline All included participants & Older adults & Relatives & Professional caregivers $^{\mathrm{a}}$ & Care service managers \\
\hline Women/men & $16 / 8$ & $12 / 4$ & $11 / 5$ & $12 / 3$ \\
\hline Age, Md (range) & $70(60-81)$ & $70(35-85)$ & $41.5(26-57)$ & $55(38-66)$ \\
\hline \multicolumn{5}{|l|}{ Highest level of education } \\
\hline University & 10 & 11 & 8 & 15 \\
\hline Secondary school & 3 & 3 & 6 & 0 \\
\hline Vocational education & 10 & 2 & 2 & 0 \\
\hline Elementary school & 1 & 0 & 0 & 0 \\
\hline Country-specific demographics & Older adults & Relatives & Professional caregivers & Care service managers \\
\hline \multicolumn{5}{|l|}{ Finland } \\
\hline Women/men & $3 / 1$ & $2 / 2$ & $3 / 1$ & $6 / 0$ \\
\hline Age, Md (range) & $74.5(70-81)$ & $65(43-70)$ & $42(37-57)$ & $43.5(38-56)$ \\
\hline \multicolumn{5}{|l|}{ Highest level of education } \\
\hline University & 0 & 2 & 2 & 6 \\
\hline Secondary school & 3 & 0 & 0 & 0 \\
\hline Vocational education & 1 & 2 & 2 & 0 \\
\hline Elementary school & 0 & 0 & 0 & 0 \\
\hline \multicolumn{5}{|l|}{ Germany } \\
\hline Women/men & $8 / 6$ & $3 / 2$ & $3 / 2$ & $2 / 3$ \\
\hline Age, Md (range) & $67.5(60-79)$ & $52(35-70)$ & $42(39-57)$ & $56(39-58)$ \\
\hline \multicolumn{5}{|l|}{ Highest level of education } \\
\hline University & 4 & 3 & 2 & 5 \\
\hline Secondary school & 0 & 2 & 3 & 0 \\
\hline Vocational education & 9 & 0 & 0 & 0 \\
\hline Elementary school & 1 & 0 & 0 & 0 \\
\hline \multicolumn{5}{|l|}{ Sweden } \\
\hline Women/men & $5 / 1$ & $7 / 0$ & $5 / 2$ & $4 / 0$ \\
\hline Age Md (range) & $72.5(69-75)$ & $73(70-85)$ & $41(26-57)$ & $56.5(41-66)$ \\
\hline \multicolumn{5}{|l|}{ Highest level of education } \\
\hline University & 6 & 6 & 4 & 4 \\
\hline Secondary school & 0 & 1 & 3 & 0 \\
\hline Vocational education & 0 & 0 & 0 & 0 \\
\hline Elementary school & 0 & 0 & 0 & 0 \\
\hline
\end{tabular}

${ }^{a}$ Registered nurses (4), assistant nurses (8), physiotherapists (2), occupational therapists (2) 


\subsection{Analysis}

The focus group discussions were analysed by qualitative descriptive analysis. This is considered the least interpretive of qualitative analysis approaches as the intention is to produce a descriptive summary of phenomena, organised in a way that best contains the collected data [62]. This first part of the analysis was made in the original language and performed by the research team in each of the three countries. All transcribed text was read and reread to capture the features associated with CRO. The sentences and paragraphs assessed as relevant, based on the aim of the study, were identified and systematically marked across the entire dataset. The core content of the generated sentences and paragraphs was identified and labelled as codes. Thereafter, all text was translated into English and the Swedish team (RMJP, CG) carried out the rest of the analysis, although all the authors reflected on the data during the process, including provision of suitable quotes reflecting the results. All the generated 674 codes were collated using ATLAS.ti. The codes were compared to find out similarities and differences, and grouped together into eight categories based on their content. As the analysis process progressed, it became apparent that the categories could be sorted under three themes, namely: What, Who/Whom and How aspects of CRO (Table 3).

\section{Results}

The data revealed three aspects of CRO: (1) What CRO is, (2) Who needs CRO and by Whom it should be given and (3) How CRO should be conducted.

These three overall themes are described in categories based on the codes that emerged in the data (Table 3). The interview extracts, provided in the categories, are marked with the country of origin: Germany (Ger), Finland (Fin) and Sweden (Swe), as well as group of origin: older adults $(\mathrm{OA})$, relatives $(\mathrm{R})$, professional caregivers (PC) and care service managers (CSM).

Table 3 Potential users' perceptions of care robot orientation

\begin{tabular}{ll}
\hline Theme & Category \\
\hline The What aspect of CRO & Basic knowledge needs \\
& Processing of care robot infor- \\
mation \\
Ethical issues \\
& Funding considerations \\
& Target groups of CRO \\
The Who/Whom aspect of CRO & Stakeholders in CRO provision \\
& CRO activities \\
The How aspect of CRO & Time aspects of CRO \\
\end{tabular}

\subsection{The What Aspect of CRO}

The theme explores the fundamental dimensions of CRO of grasping What care robotics is, the definition, how care robots can be used, possible benefits of using them and an understanding of the context in which care robot use can be beneficial. In exploring and accepting something new, it is fundamental to have a basic understanding of what that something is or could be. In situations when this understanding is lacking, it is problematic to know what to ask, and to contextualise possible use in everyday life. In contrast, when a basic idea of this exists, it is possible to discuss other aspects and considerations of the area, and to experience increased orientation.

The theme framing What CRO is consists of four categories: basic knowledge needs, processing of care robot information, ethical issues and funding considerations.

\subsubsection{Basic knowledge Needs}

The state of a lack of knowledge and experience in the field is evident, according to the informants, and it explains an initial existing scepticism towards care robots. When knowledge within the field is lacking, it is problematic to know what to ask for or where to look for the information:

[...] probably when it becomes more topical and closer to myself that now you need to get one, I would probably know how to ask for the information. But since I don't think I need it now, I don't even know what to ask for and what kind of information I would need. (Fin: OA)

Initially, the term welfare technology, care robots specifically, needs to be defined to reduce fears and prejudice and to overcome unjustified scepticism. This is exemplified in a changing attitude when being more informed:

So, my opinion already changed compared to the first statement about what I think about using robots [in this interview]. After seeing the film and the documents here, I don't think I could have imagined it and suddenly now I could, yes, I could imagine it. So, it's a question of informing people. (Ger: OA)

The need for basic knowledge in CRO refer to information intended to increase the knowledge, understanding and conceptualisation of care robot use in daily life. To fill the knowledge gaps, answers are required for various questions about care robots, such as what kind of care robots are available, which features do they have and what chores can they perform. These questions are related to how care robots could support professional caregivers as well as older adults and their relatives, currently, and future expectations and possible areas of use. 'You should emphasise the benefits 
[...] through the benefits, people will understand. If you just say we're doing this, there will be resistance, but if you start from the benefits' (Fin: R).

Not only general information is requested, but also more specific positive examples regarding benefits with care robots related to individuals' specific needs. These examples should be connected to various disabilities, illnesses or other situations, where care robots can be supportive: '[...] even if you are interested in technical development and so [...] if you are in a difficult situation, then you focus very much on your own little part in this and it is that specific information you want' (Swe: R).

The contrary aspect is also discussed, when care robot use might not be suitable: 'I have a hard time to see it [care robots] used in dementia care [...] this is a big concern I have, because they need so much care, conversation and body language' (Swe: CSM). In addition, older adults are concerned about practical issues related to how to manage and approach a care robot, and lack of space in the housing.

The need for basic knowledge in CRO should be seen in the light of potential users having different starting points in level of knowledge, understanding and reasoning, partly depending on having caring needs in daily life or not: 'At first I have to experience it (the robot) before I am getting ill and can probably no longer make my own decisions' (Ger: OA).

\subsubsection{Processing Care Robot Information}

The category describes the management of information about care robots. It is not just about passively receiving information. When the information is known, it is also necessary to conceptualise it in different scenarios in one's own process of understanding and imagine one's benefits from it. It is about processing the information and turning it into practical know-what and know-how, about managing the technology - care robots. From a managerial and professional perspective, it is also a process of putting the knowledge in an authentic context for practical application; for example, the needs of environmental factors, service structures, technology demands and training and changed work routines. Another prevailing perspective is that the use of care robots must be guided by the specific needs of the potential users: 'There's always the question, whether it's robotics or any other kind of technology $[. .$.$] what problem$ this solves, and on the other hand, what problem does it not solve' (Fin: CSM). There are also aspects related to legal and safety issues involved in the process, like what happens if mistakes or damages occur, caused by the care robot, as well as concerns about data security and integrity issues.

Overcoming prejudices and a common suspicion that the driving purpose is only a financial incentive with welfare technology in general could be challenging:
We must not forget about information and explanations both to older adults and relatives, regarding the purpose $[\ldots]$ I think that is very important, because I think that they instantly believe that the purpose of new innovations is to save staff and make cutbacks, perhaps deteriorate things. (Swe: CSM)

To avoid such suspicions, a distinct communication is needed about reasons and intentions with the use of care robots. When these suspicions are resolved, an open-minded attitude beneficial for CRO can be experienced.

\subsubsection{Ethical Issues}

The significance of ethical orientation in the field of CRO has been highlighted. A main ethical issue is the importance of using care robots carefully and competently founded on ethical values. For meeting these requirements, there is an apparently explicit request for ethical guidelines, legislations and needed professional competences. This also appears as a request for reliable service, support and technology functions using care robots. In this category, an aspiration for competent and agile communication is highlighted, to clarify, understand and trust that the intention with using care robots is not to replace human caregivers, but ensure that care robots are complementary to professional caregivers. This suspicion is addressed in the following quote:

If a certain robot was to be introduced in one care unit and we [professional caregivers] were supposed to focus on the social part, one might think that we would get more time for that [the social part] but then the effect would be that they will remove staff, probably [...] I would not want them to replace staff, but they will do that. (Swe: PC)

Given that the issue of compulsory use of care robots has arisen, it is worth acknowledging that this is an issue having at least two implications. On the one hand, it could be compulsory in certain situations, which might be offered from public care, referring to staff shortage and funding issues: 'Here's how care is done, this is a help we offer you [...] if it is cameras or a timer for the stove, there are a lot of such things $[\ldots]$ it's nothing strange' (Swe: OA). On the other hand, the need for sensitivity in introducing care robots is emphasised, implying that care robots shouldn't be forced on people: 'In the end, the user decides how far he or she wants to get involved with technology or whether he or she chooses the classic way of human care' (Ger: OA).

\subsubsection{Funding Considerations}

The aspect of funding considerations calls for awareness and discussions about the welfare system. If there are financial 
benefits in using care robots, these might be the first choice when offering tax-funded care to older adults needing support in daily life: 'As a starting point, it's the municipalities' business to pay for it, if the robot is absolutely necessary' (Fin: OA). In these cases, it may not be optional, since the economy in the welfare system is limited. Tax-funded care robots bring up discussions about which care needs can be considered as the basic level for funding by the welfare system, and when does it become the individuals' responsibility. If the care robots are not offered by the welfare system, an alternative might be to purchase your own care robot, if preferable, instead of having the support of professional or informal caregivers: ' $[\ldots]$ if you have a lot of money, you buy your own robot' (Fin: OA). However, this alternative raises questions about possible inequities based on different economic conditions:

Is this a merchandise, or is this our common right, will this mean that those who have the opportunity . . . intellectually, economically in terms of resources [...] they can choose this, but all the others who do not have that, how to handle them... we are getting a very divided society. (Swe: OA)

Another alternative could be care robots funded by health care insurance: 'I could imagine that the health insurance company would be happy to make it available free of charge, because it would keep labour costs as cheap as possible. That's probably how it's going to happen' (Ger: CSM). A political philosophy aspect was revealed, given voice in the quotation: 'Of course it's always the one who benefits the most that should be the biggest payer. In many cases, we're talking about society [...]' (Fin: R). A suggested alternative was care robots/welfare technology 'libraries' for periodic needs of this kind of technology.

\subsection{The Who/Whom Aspect of CRO}

The theme covers the groups of the recipients of CRO and the stakeholders and other actors conducting activities to increase CRO. The main target group of CRO includes those with needs who are expected to receive the support of care robots in daily life; in this case, primarily older adults with caring needs, but also relatives and professional caregivers. The group of professional caregivers and care service managers express the need for increased knowledge of care robot possibilities in their caring practice, but also for having a primary responsibility in CRO to the two former previously groups: older adults and relatives. A variety of stakeholders is suggested to provide the necessary orientation to the potential users of care robots, including people in one's immediate surroundings, professionals and institutions and organisations on the societal level.
The next theme framing the Who/Whom aspect in CRO consists of two categories: target groups of CRO and stakeholders in CRO provision.

\subsubsection{Target Groups of CRO}

People with caring needs appear to be the primary target group of CRO and secondary is their relatives, often acting as informal caregivers. The primary group addressed the assumption that one is best susceptible to CRO when having the actual need for it. The professional caregivers are mentioned as an important target group, given their responsibility for providing care robot information. Positive attitudes among the professional caregivers are considered crucial for the introduction and use of care robots to succeed. Different categories of professional caregivers are expected to provide $\mathrm{CRO}$; however, they are often not considered to possess the sufficient competence and recourses in this given responsibility, neither by their own nor the other potential users' point of view: ' $[\ldots]$ in a nursing home there should be health care professionals who have the knowledge . . . but I don't know if they do, but that is how it should be' (Swe: R). An increased level of knowledge would be necessary for all professional caregivers. As an extension of the discussion, a need for a new specialist profession in the area is addressed.

Care service managers are considered to be an important target group as leaders of the process of change, in terms of providing information and development of skills and working procedures. They also need to deal with upcoming problems and difficulties in the implementation of care robots, including motivating and supporting all involved parties: 'What is most difficult, I think, experience wise, is to keep the motivation up and running with our professional caregivers, because you very easily fall back to what has been before' (Swe: CSM).

In addition to the potential users, the more general societal need for increased CRO is highlighted. Improved CRO may change attitudes, especially when considering one's own caring needs situation and the possibilities for staying independent in the private home:

So now we're going to take this as our starting point. The Care-O-bot in any case, I would let it immediately into my apartment, if it would be necessary. If I could postpone a move into an assisted living for several more years.

I would definitely prefer that (care robot), before I have to go to a nursing home. (Ger: OA)

\subsubsection{Stakeholders in CRO Provision}

A common understanding is that too little is known on the subject of a good foundation for CRO. From the 
perspective of older adults, it seems adequate that the information should come from professional caregivers. When care needs arise, involved professionals should suggest appropriate care including CRO: 'Yes, but everyone has a contact with the health service, if you are ill then you have that contact, then that contact should be the one who gives the information' (Swe: R). However, older adults and relatives suggest that this is not accomplished because of a lack of knowledge in the area among most professional caregivers, as well as time constraints.

Other identified important sources in a more general discourse are family, friends and peers, who in daily conversation might discuss care robots and offer practical support. The information is considered to become more credible if the persons themselves have experience of using the product/robot:

Maybe it's the peer aid, peer support, peer information on every level, so that users could tell future users, or the older adults who have been helped by care robots, could tell about their hopefully good experiences, and $[\ldots]$ reduce distrust and fear. (Fin: $\mathrm{R})$

CRO provided by technical experts in collaboration with professional caregivers is suggested as an optimal strategy for CRO:

So, I could even imagine that a new profession would emerge, for example medical engineering, technology and nursing. Combining these together in one occupation and perhaps initially financed by industry. With the health insurance companies, of course, because they must finance it afterwards [...]. (Ger: $\mathrm{OA})$

Seen from a general perspective, several stakeholders are mentioned in relation to provision of CRO. Official sources (governmental, regional and local authorities) are considered to have an official task for providing CRO in the national field of welfare technology information. Research and educational institutions are other stakeholders, regarded as a reliable CRO source. The manufacturers and suppliers of welfare technology and care robots also have an important role in CRO. However, the risk of bias in their trustworthiness is discussed: 'I don't immediately trust anything that I get from a salesperson. Of course, they just want to sell the product [...]' (Fin: CSM).

Concerning the general information from media and society as a whole, there are many possible channels; some mentioned the Internet and social media. Television, newspapers and advertising are also considered to be important actors in CRO. Other information channels, such as information in shops, pharmacies, fairs and independent advice centres for robots, are suggested:
Make it exciting, that it is pleasurable and that I see it on different social media, I see it in stores, I see it in movies, celebrities have a small robot. I think it is difficult to just introduce it in elder care, instead we have to make sure that this technology is visible and used by others also [not just older adults]. (Swe: OA)

On a more formal level, CRO can be given as community information in different places and situations. In particular, centres for older adults' services, different care settings, theme-days arranged by seniors, centres for relatives and retirement organisations are mentioned:

So, I always think it would be nice if there's some kind of external person who doesn't want to sell me this robot and just tell me how great the device could be, but that you really get honest information about advantages and disadvantages. [...] (Ger: R)

Field trips and information through human interaction are highlighted as important CRO arenas. In Germany, which has a different welfare system in comparison to Finland and Sweden, health care insurance companies also play an important role in providing information as a part of the general CRO.

\subsection{How CRO Should be Conducted}

CRO can be conducted in different knowledge improvement activities, from targeted information to more general governmental societal campaigns. As concerns the time aspect of CRO, it is discussed that the most beneficial learning/ orientation is experienced when someone has actual needs that can be solved by welfare technology in the form of care robots. On the other hand, other time aspects indicate that CRO should be provided in advance, even to young people in schools.

The theme framing the How aspect of CRO consists of two categories: CRO activities and time aspects of CRO.

\subsubsection{CRO Activities}

So far, CRO activities are occurring sparingly according to the potential users: '. . . you have to search for yourself . . . the channels that exist ... if you are curious and interested ...' (Swe: R). However, it is suggested that CRO activities, on an individual or group level, imply giving an introduction and information presented in a positive manner. The information must be simple and adapted to the receivers, regardless of target group: '. . . for us older adults, when technology is taught, it should be taught in such a way that people really get it ...' (Fin: OA). It must be clear, descriptive and motivate the incentive of care robot use. For example, to overcome the initial assumptions that it is only 
about saving money. Another important aspect is that the activities should have understandable examples offering the CRO receivers related to cases of care robot implications and care robot efforts. If possible, it is anticipated that the learning and improved CRO will have increased results by using the didactics of 'learning by doing' and hands-on possibilities. Positive orientation activities are also described as being more effective in safe and permissive environments with joint learning attempts, also having long duration in test periods. The CRO should preferably be conducted in the environment and settings where the care robot will be used, while continuous CRO and training are desired, particularly among professional caregivers, partly due to high staff turnover.

\subsubsection{Time Aspect of CRO}

Another aspect how CRO should be conducted is when, in time, it is beneficial and most effective. One issue about this was raised in expectation that information should best be given when a person has needs and when it is relevant to a changed life or work situation that perhaps could be solved by care robots. Only then is it possible to put oneself into the situation and ask the right questions. On the other hand, there is an incentive to offer CRO, on a more general level as common information for peoples' awareness of the possibilities for care robots. Improvements in the general CRO would have positive effects on the day when the individual or a relative and a professional have the needs or are facing care robot implementation. Seen from the perspective of older adults, it is discussed that they should be oriented before they become too old and frail to make their own decisions: 'Technology needs to be introduced earlier in life, before people become affected by old age and illness' (Ger: OA). However, many lack interest since they believe that care robot use is far ahead in the future and does not concern them yet. Thus, effective CRO seems to occur when it is motivated by an individual's curiosity or interest in the issue.

Another time aspect of CRO is that it is a generational issue. The young people of today will be better prepared and probably not consider care robots to be something odd. It is suggested that to get used to the technology, it should be introduced and discussed at an early stage in school: 'I think that even the next generations, those that have integrated technology, robotics and artificial intelligence in their professional lives, want robots for their care in future, too' (Ger: CSM). However, the time aspect of CRO might also have a dimension of an expiration date, due to the rapid technology development. The use of care robots in elder care is also predicted to be a natural part of the care:

[...] I think, later, it will be like, one care unit realises

$[\ldots]$ we don't have staff, we have to introduce it [care robots]. Then I think the technology exists, then there are probably ... intelligent homes that can explain to someone who might be demented ... explain that now we will do this and that. (Swe: PC)

\section{Discussion}

\subsection{The What Aspect of CRO}

The findings reveal an evident lack of orientation in the field of care robots in elder care. CRO activities are so far sparse, and the potential users wish to learn more. Basic knowledge is required to increase the understanding and conceptualisation of care robot use in daily life. Primary issues concern general questions about what a care robot is, what it can do and what is available on the market. Detailed information was also requested concerning benefits related to the individuals' specific needs. Khosravi and Ghapanchi [19] refer to similar results, arguing that the anticipated effects of the use of care robots must be promoted if they are to be accepted and used. Promoted anticipated benefits can be related to independent living, increased safety, increased social connectedness and advances in mobility. It is important that CRO reach all concerned potential users, as is also referred to in previous studies $[17,21,66]$. Consequently, it is not acceptable that some appoint themselves as spokesmen for others, for example older adults, though not fully understanding their needs, expectations and wishes, nor should CRO rely on the prevailing stereotypical perceptions [21] of older adults.

CRO additionally needs to be processed and turned into practical know-what and know-how. It is about transferring the knowledge into an authentic context, care units or private homes, which is a process involving aspects of the environment, service structure and training needs as well as, for example, legal, data security issues. However, first, people need to be made aware of the existence and possibilities of the technology. There seems to be a suspicion, at least initially, of the incentive to initiate the use of care robots, as it can be associated with staff reductions, savings or usability, as has also been described in previous research [31, 67]. Therefore, the intentions and expected benefits need to be clearly communicated during the whole CRO process. This also applies to future studies, which need to demonstrate effects and how the robots can solve real problems in order to shift from novelty to functionality in elder care [68].

Ethical aspects are considered important among the potential users. This finding is consistent with previous research suggesting that care robots are tolerated as assistive tools for monitoring, communication, rehabilitation and such, but are more questioned as companions or for relieving anxiety and loneliness $[46,50,52]$. Another view was that 
care robots should not be forced on older adults. The ethical aspect becomes even more evident in relation to older adults having reduced decision-making ability, especially when CRO was discussed in relation to vulnerable older adults suffering from cognitive impairment. In contrast to these findings, a relatively optimistic view of technologies to support people with dementia in everyday life is presented in a recently published review [69]. From the professional caregivers' perspective, there is a possibility that care robots are regarded as a threat to the fundamental values of care. These assumptions suggest that rigorous ethical reflections are required to evaluate the values of care robot use and consequences in the professional caregiver-patient relationship [39, 70]. Also, the European Parliament underlines that human contact is one of the fundamental aspects of care, and replacing humans with care robots could dehumanize caring practices. However, they also recognize that care robots could perform automated tasks and thereby facilitate the work of professional caregivers [71].

The issue of financing the care robots is one of the central aspects of the findings. The potential users were all aware of the impending demographic challenges, lack of professional caregivers and financial resources and that actions are required, such as increased use of welfare technology. However, the aspect of who should pay gave rise to many questions. While it appeared that care robots should be financed by public health care or social care, based on the prevailing systems in Sweden and Finland, there was an awareness of the difficulties in determining when the responsibilities of the welfare system end and become the individuals' responsibility. Subsequently, the economical fundament must be explored, scrutinised and motivated in cost-benefit analyses performed with consideration to the variables appropriate for the particular country [72], but still, with a firm footing in the fundamentals of care and respect for human values.

\subsection{The Who/Whom Aspect of CRO}

The primary target group for CRO is clearly older adults. Relatives, acting as informal caregivers, and professional caregivers also need to be properly addressed. In previous research, the professional caregivers are described as having less experience with and more concerns about robots than older adults do and the population in general [51, 73, 74]. One possible explanation could be that the literature has not really addressed the technical integration in care or how the professionals can assist vulnerable older adults in the selection and use of care robots [29,53]. CRO does not generally seem to be that high on the agenda among professional caregivers in elder care, despite awareness of the coming challenges. The professional caregivers are perhaps more concerned about problems in their daily practice, than in actively seeking information about care robots. Still, it could be argued that professional caregivers should embrace the use of care robots, since these can decrease their workload [75] and subsequently release time for human interactions. Thus, major efforts are needed to reach this target group and to provide accessible information as well as involve them in the development of useful technology, as also stated by, for example $[17,61]$. By adopting a user-centred approach, the functions can better match the end-user's needs and wishes, and this, of course, applies to all potential users. A user-centred approach should characterise the whole CRO process, from design to implementation, instead of technical ambitions, which seem to be what is presently guiding the development of robots [30,31]. This perspective is in accordance with the mutual shaping framework [76], which proposes user involvement in early stages, based on the understanding that social values and the meaning of technology should be questioned throughout the process of design, thus highlighting the importance of co-production between robotics and society. For that purpose, participatory design can be applied; a process building on participants' self-identified issues and concerns. By entering the co-designer role, older adults and care professionals have an opportunity to conceptualize care robots in their daily life, including the capabilities and potential application areas [77].

Several stakeholders, on different levels, are required to ensure the best foundation for CRO. On a micro-level, the professional caregivers, family, friends and peers are pointed out. The professional caregivers are considered to be important stakeholders since they are expected to provide CRO and support to older adults, when needs arise. Considering that professional caregivers additionally constitute a main target group, they seem generally unprepared for this task. According to previous findings, the professional caregivers' intention to introduce care robots depends upon the individual's knowledge and attitude towards robots and a sense of control regarding their use, which is one reason why great efforts need to be placed on their CRO [52]. The question is if they even can be expected to meet these requirements. New strategies are required in involvement and collaboration with technical experts or suppliers, or new professions with combined competences. In the findings, media appeared to be an important player in CRO. Up to now, care robots have been quite invisible in media, and the primary way to get information has been to actively seek for it oneself on the Internet. Consequently, a sober long-term time plan would be needed for the stakeholders involved, including at both the micro and macro level, to provide solid and well-founded CRO.

\subsection{The How Aspect of CRO}

CRO activities are initially needed to increase awareness of the possibilities with care robots. If care robots are to 
be implemented they need to be accepted by the potential users [17]. Previous studies refer to that care robots are viewed more positively after personal experience [51, 58]. We found that a short video and pictures were enough to affect the potential users, which could suggest that not much is required to change people's attitudes. The time aspect is important to consider, when CRO activities should take place. CRO is probably most effective when it is needed, however, then not everyone might be receptive to the information, which is why a general level of CRO in society should be striven for.

The question of how CRO should be addressed in the authentic contexts could be summarised as, that it should be motivating and adapted to the potential user. This may for example relate to ways of communicating, providing hands-on possibilities and meeting possible fears and concerns about using the technology. Another aspect of the time dimension is to consider the predicted expiration date, due to the rapid development of technology. This may have the effect that professionals working with CRO need to work in parallel with constant monitoring of the rapid development of welfare technology but also consider the infrastructural aspects of significance, when taking a holistic perspective. It is known that culture influences caregiving (see for example Revenson et al.) [78], but also within cultures there are caregiving differences. However, indications for cultural differences were not apparent in the present study except as regards aspects related to the represented countries' different welfare systems.

\subsection{Methodological Considerations}

The objective of the present study, to explore perceptions of CRO, can be considered quite wide-ranging. This was however a conscious choice, motivated by a novel attempt to capture the overall meaning of orientation and in relation to potential users of care robots. The wide-ranging approach is justified based on the ignorance and inexperience still prevailing in the area. However, the perceptions of the individual user groups need to be explored further. The qualitative descriptive study design was considered appropriate, as these designs typically are an eclectic but reasonable combination of sampling, data collection and representational techniques. A purposeful sampling technique was used for recruitment, since the goal was to obtain informants deemed information-rich for the purpose of the study $[62,63]$. This approach might increase the risk that the included informants had a more positive view compared to potential users in general. However, the opposite could also be reflected, that they agreed to participate due to being sceptical and wanting to express their concern. This is also in line with our experiences, as both attitudes were evident during the focus group discussions. Initially, the informants tended to be somewhat negative and suspicious, but that altered during the discussions. The informants' background might also affect the outcomes. For example, a majority had an academic education, which is partly explained by professional caregivers and care service mangers being university graduates. Many of the relatives also had a university degree, while the level of education among the older adults was more varied. Most informants were women (41 of 71), but that is how the demographic looks in higher age as well as among professional caregivers.

Few of the informants had previously reflected on care robots. Therefore, the focus group format was particularly suitable, as the group dynamics assisted the informants to actively clarify their perceptions. The group homogeneity may have been a limitation, since diversity in the composition of the group may enhance discussion. However, there was an overwhelming risk of informants being inhibited by hierarchical structures or interdependence between, for example, the caregivers and care service managers, had the groups been heterogeneous. During the focus group discussions, the informants watched a video clip and viewed pictures of various examples of care robots instead of being directly confronted with the technology. According to Woods et al. [79], videotaped trials have potential as a technique for testing human-robot interactions. In the current study, the video clips gave an opportunity to show various examples of care robots, which was necessary since most of the informants lacked knowledge in the field, and it was essential that they had a common and accurate picture of what kind of technology the focus group discussion referred to. One can argue that the perceptions could vary depending on which care robots the video clip and pictures referred to; however, a variety of pictures was presented, showing examples of care robots providing support in daily tasks, communication, monitoring behaviours and companionship.

One measure to ensure the trustworthiness of the study was that the focus group discussions were conducted by a moderator and assistant moderator and followed an interview guide constructed in collaboration with all the involved researchers. All the researchers were also involved in the manuscript preparation and contributed to achieving confidence in the truth of the data and their interpretation [80].

\section{Conclusion and Clinical Impact}

The need for CRO is general in society. If knowledge in the field is lacking, it is nearly impossible to know what to ask for or seek information about. Lack of knowledge also easily creates false impressions concerning robots' capabilities and risks. Therefore, introducing CRO must be founded on an agile implementation plan for care robots, having a basis in trustworthy knowledge and information 
and respecting the individual's wishes. This also requires an ethical management structure when care robots are offered to people having reduced decision-making ability (dementia, cognitive impairment) and raises the issue of who then should make the decision. The professional caregivers also require extensive CRO based on their key role as users, providers and instructors of care robots in elder care, tasks they appear to be relatively unprepared for.

The mapping of the What, Who/Whom and How aspects of CRO offers a foundation for the creation of CRO models, which might facilitate structured and goal-oriented CRO strategies. The map provides an overall understanding of the potential users' perspectives. It thereby offers a compilation of aspects to consider when seeking to increase the knowledge, understanding and conceptualisation of care robots in elder care; the What aspect, addressing general basic knowledge needs and the processing of those into practice; the Who/Whom aspect, focusing on the recipients and actors of CRO; and finally, the How aspect, proposing actual $\mathrm{CRO}$ activities.

Acknowledgements Open access funding provided by Mälardalen University. We cordially thank all informants, who generously shared their experiences and thoughts about welfare technology and care robots. This study was supported by the ORIENT project under JTC 2017 launched by JPI MYBL. The support of JPI MYBL and the national funders within the JPI MYBL framework is gratefully acknowledged (Award No. 2017-02300 by Forte, Sweden; Award No. 16SV7954 by the Federal Ministry of Education and Research, Germany, and Award No. 318837 by the Academy of Finland).

\section{Compliance with Ethical Standards}

Conflict of interest The authors declare that they have no conflict of interest.

Open Access This article is licensed under a Creative Commons Attribution 4.0 International License, which permits use, sharing, adaptation, distribution and reproduction in any medium or format, as long as you give appropriate credit to the original author(s) and the source, provide a link to the Creative Commons licence, and indicate if changes were made. The images or other third party material in this article are included in the article's Creative Commons licence, unless indicated otherwise in a credit line to the material. If material is not included in the article's Creative Commons licence and your intended use is not permitted by statutory regulation or exceeds the permitted use, you will need to obtain permission directly from the copyright holder. To view a copy of this licence, visit http://creativecommons.org/licenses/by/4.0/.

\section{References}

1. World Health Organization (2015) World report on ageing and health 2015. https://www.who.int/ageing/events/world-repor t-2015-launch/en/. Accessed 24 June 2019

2. United Nations Department of Economic and Social Affairs, Population Division. World population ageing 2015 (ST/ESA/
SER.A/390). http://www.un.org/en/development/desa/popul ation/publications/pdf/ageing/WPA2015_Report.pdf. Accessed 24 June 2019

3. United Nations. World Population Prospects 2015 (1). http:// esa.un.org/unpd/wpp/Publications/Files/WPP2015_Volum e-I_Comprehensive-Tables.pdf. Accessed 24 June 2019

4. Becker P, Schütz J, Zimmermann A (2018) Ageing Workforce, Social Cohesion and Sustainable Development: Political Challenges within the Baltic Sea Region. Population Europe Discussion Paper. p. 61. https://www.population-europe.eu/file/3058/ download?token=DIcbQksA. Accessed 24 June 2019

5. Nordic Welfare Centre. Welfare technology. https://nordicwelf are.org/en/welfare-policy/welfare-technology/. Accessed 30 April 2019

6. Hofmann B (2013) Ethical challenges with welfare technology: a review of the literature. Sci Eng Ethics 19(2):389-406. https ://doi.org/10.1007/s11948-011-9348-1

7. Harrefors C, Sävenstedt S, Axelsson K (2009) Elderly people's perceptions of how they want to be cared for: an interview study with healthy elderly couples in Northern Sweden. Scand J Caring Sci 23(2):353-360. https://doi.org/10.111 1/j.1471-6712.2008.00629.x

8. Okamura AM, Mataric MJ, Christensen HI (2010) Medical and health-care robotics. IEEE Robot Autom Mag 17(3):26-37

9. ISO/TR 23482-2-2:20 (2019) Robotics—application of ISO 13482 - part 2: application guidelines

10. Harper C, Virk G (2010) Towards the development of international safety standards for human robot interaction. Int J Soc Robot 2(3):229-234

11. Glende S, Conrad I, Krezdorn L, Klemcke S, Krätzel C (2016) Increasing the acceptance of assistive robots for older people through marketing strategies based on stakeholders needs. Int J Soc Robot 8:355-369

12. Goeldner M, Herstatt C, Tietze F (2015) The emergence of care robotics - a patent and publication analysis. Technol Forecast Soc Change 92:115-131

13. Fried LP, Ferrucci L, Darer J, Williamson JD, Anderson G (2004) Untangling the concepts of disability, frailty, and comorbidity: implications for improved targeting and care. J Gerontol 59(3):M255-M263

14. Broadbent E, Stafford R, MacDonald B (2009) Acceptance of healthcare robots for the older population: review and future directions. Int J Soc Robot 1(4):319

15. Lee C, Coughlin JF (2015) PERSPECTIVE: older adults' adoption of technology: an integrated approach to identifying determinants and barriers. J Prod Innov Manage 32(5):747-759

16. Michael J, Salice A (2017) The sense of commitment in humanrobot interaction. Int J Soc Robot 9(5):755-763

17. Linzer N (2002) An ethical dilemma in home care. J Gerontol Soc Work 37(2):23-34

18. Herstatt C, Kohlbache, F, Bauer P (2011). Silver product design - product development for older people. Working Paper No. 65, Institute for Technology and Innovation Management. Hamburg University of Technology

19. Khosravi P, Ghapanchi AH (2016) Investigating the effectiveness of technologies applied to assist seniors: a systematic literature review. Int J Med Inform 85(1):17-26

20. García-Soler Á, Facal D, Díaz-Orueta U, Pigini L, Blasi L, Qiu R (2018) Inclusion of service robots in the daily lives of frail older users: a step-by-step definition procedure on users' requirements. Arch Gerontol Geriatr 74:191-196

21. Frennert S, Östlund B (2014) Review: seven matters of concern of social robots and older people. Int J Soc Robot 6(2):299-310

22. Hudson J, Orviska M, Hunady J (2017) People's attitudes to robots in caring for the elderly. Int J Soc Robot 9(2):199-210 
23. Wu Y-H, Fassert C, Rigaud A-S (2012) Designing robots for the elderly: appearance issue and beyond. Arch Gerontol Geriatr 54(1):121-126

24. Graf B, Reiser U, Hägele M, Mauz K, Klein P (2012) Robotic home assistant Care-O-bot ${ }^{\circledR} 3$ - product vision and innovation platform. Adv Robot Soc Impacts (ARSO). https://doi. org/10.1109/ARSO.2009.5587059

25. Cavallo F, Limosani R, Manzi A et al (2014) Development of a socially believable multi-robot solution from town to home. Cognit Comput 6:954-967. https://doi.org/10.1007/s1255 9-014-9290-z

26. Melkas H, Hennala L, Pekkarinen S, Kyrki V (2016) Human impact assessment of robot implementation in Finnish elderly care. In: International Conference on Serviceology, pp 202-206

27. Gustafsson C, Svanberg C, Müllersdorf M (2016) A robotic cat in dementia care-a pilot study. ISG 2016. In: World conference of gerontechnology, vol 15, pp 151-151

28. Wada K, Shibata T, Musha T, Kimura S (2005) Effects of robot therapy for demented patients evaluated by EEG. Paper presented at the 2005 IEEE/RSJ international conference on intelligent robots and systems

29. Sharts-Hopko N (2014) The coming revolution in personal care robotics. What does it mean for nurses? Nur Adm Q 38:5-12. https://doi.org/10.1097/NAQ.0000000000000000

30. Bedaf S, Gelderblom GJ, De Witte L (2015) overview and categorization of robots supporting independent living of elderly people: what activities do they support and how far have they developed. Assist Technol 27(2):88-100

31. Broadbent E, Tamagawa R, Patience A (2012) Attitudes towards health-care robots in a retirement village. Aust J Ageing 31(2): $115-120$

32. ISO 13482 (2014) Robots and robotic devices—safety requirements for personal care robots

33. Jacobs T, Virk GS (2014) ISO 13482-The new safety standard for personal care robots. In: Conference ISR ROBOTIK 2014, pp 698-703

34. Moyle W, Jones C, Pu L, Chen S-C (2018) Applying user-centred research design and evidence to develop and guide the use of technologies, including robots, in aged care. Contemp Nurse 54(1):1-3. https://doi.org/10.1080/10376178.2017.1438057

35. Tuisku O, Pekkarinen S, Hennala L, Melkas H (2019) 'Robots do not replace a nurse with a beating heart': the publicity around a robotic innovation in elderly care. Inf Technol People 32(1):47-67

36. Peek STM, Wouters EJM, van Hoof J, Luijkx KG, Boeije HR, Vrijhoef HJM (2014) Factors influencing acceptance of technology for aging in place: a systematic review. Int J Med Inform 83(4):235-248

37. Lin P, Abney K, Bekey GA (2014) Robot ethics: the ethical and social implications of robotics. MIT Press, Cambridge

38. Seibt J, Hakli R, Nørskov M (eds) (2014) Sociable robots and the future of social relations. In: Frontiers in artificial intelligence and applications, vol 273. IOS Press, Amsterdam

39. Vandemeulebroucke T, de Casterlé BD, Gastmans C (2018) How do older adults experience and perceive socially assistive robots in aged care: a systematic review of qualitative evidence. Aging Ment Health 22(2):149-167

40. Sharkey A, Sharkey N (2012) Granny and the robots: ethical issues in robot care for the elderly. Ethics Inf Technol 14(1):27-40

41. Young JE, Hawkins R, Sharlin E, Igarashi T (2009) Toward acceptable domestic robots: applying insights from social psychology. Int J Soc Robot 1:95-108

42. Shibata T (2012) Therapeutic seal robot as biofeedback medical device: qualitative and quantitative evaluations of robot therapy in dementia care. Proc IEEE 100(8):2527-2538. https://doi. org/10.1109/JPROC.2012.2200559
43. Pfadenhauer M, Dukat C (2015) Robot caregiver or robot-supported caregiving? Int J Soc Robot 7(3):393-406. https://doi. org/10.1007/s12369-015-0284-0

44. European Commission and European Parliament (2017) Eurobarometer 87.1. TNS statement [manufacturer]. GESIS data archive, Cologne ZA6861 Data file version 1.2.0. https://doi. org/10.4232/1.12922

45. Eftring H, Frennert S (2016) Designing a social and assistive robot for seniors. Z Gerontol Geriatr 49(4):274-281

46. Jenkins S, Draper H (2015) Care, monitoring, and companionship: views on care robots from older people and their carers. Int J Soc Robot 7(5):673-683

47. Louie W-YG, McColl D, Nejat G (2010) Acceptance and attitudes toward a human-like socially assistive robot by older adults. Assist Technol 26(3):140-150

48. Neven L (2010) 'But obviously not for me': robots, laboratories and the defiant identity of elder test users. Sociol Health Illn 32(2):335-347. https://doi.org/10.1111/j.1467-9566.2009.01218.x

49. Nilsen ER, Dugstad J, Eide H, Gullslett MK, Eide T (2016) Exploring resistance to implementation of welfare technology in municipal healthcare services-a longitudinal case study. BMC Health Serv Res 16(1):657

50. Wolbring G, Yumakulov S (2014) Social robots: views of staff of a disability service organization. Int J Soc Robot 6(3):457-468

51. Turja T, Van Aerschot L, Särkikoski T, Oksanen A (2018) Finnish healthcare professionals' attitudes towards robots: reflections on a population sample. Nurs Open 5(3):300-309

52. Rantanen T, Lehto P, Vuorinen P, Coco K (2018) The adoption of care robots in home care-a survey on the attitudes of Finnish home care personnel. J Clin Nurs 27(9-10):1846-1859

53. Archibald Mandy M, Barnard A (2017) Futurism in nursing: technology, robotics and the fundamentals of care. J Clin Nurs 27(11-12):2473-2480

54. Salzmann-Erikson M, Eriksson H (2018) A descriptive statistical analysis of volume, visibility and attitudes regarding nursing and care robots in social media. Contemp Nurse 54(1):88-96

55. Moyle W, Bramble M, Jones CJ, Murfield JE (2019) 'She had a smile on her face as wide as the Great Australian Bight': a qualitative examination of family perceptions of a therapeutic robot and a plush Toy. Gerontologist 59(1):177-185. https://doi.org/10.1093/ geront/gnx 180

56. Nomura T, Kanda T, Suzuki T (2006) Experimental investigation into influence of negative attitudes toward robots on human-robot interaction. AI Soc 20(2):138-150

57. Savela N, Turja T, Oksanen A (2018) Social acceptance of robots in different occupational fields: a systematic literature review. Int J Soc Robot 10(4):493-502

58. Heerink M, Kröse B, Evers V, Wielinga B (2010) Assessing acceptance of assistive social agent technology by older adults: the Almere model. Int J Soc Robot 2(4):361-375. https://doi. org/10.1007/s12369-010-0068-5

59. Flandorfer $P$ (2012) population ageing and socially assistive robots for elderly persons: the importance of sociodemographic factors for user acceptance. Int J Popul Res, Article ID 829835. https:// doi.org/10.1155/2012/829835

60. Varnum MEW, Grossmann I, Kitayama S, Nisbett RE (2010) The origin of cultural differences in cognition: the social orientation hypothesis. Curr Dir Psychol Sci 19(1):9-13

61. Ienca M, Jotterand F, Vică C, Elger B (2016) Social and assistive robotics in dementia care: ethical recommendations for research and practice. Int J Soc Robot 8(4):565-573

62. Sandelowski M (2000) Whatever happened to qualitative description? Res Nurs Health 23(4):334-340

63. Patton MQ (2015) Qualitative research \& evaluation methods, 4th edn. Sage Publication, Newbury Park 
64. Krueger RA, Casey MA (2015) Focus groups, 5th edn. Sage Publications, Thousand Oaks

65. Zorarobots. http://zorarobotics.be/index.php/en/ Accessed 25 June 2019

66. Bemelmans R, Gelderblom GJ, Jonker P, de Witte L (2012) Socially assistive robots in elderly care: a systematic review into effects and effectiveness. J Am Med Dir Assoc 13(2):114-20.e1

67. Beedholm K, Frederiksen K, Frederiksen A-MS, Lomborg K (2015) Attitudes to a robot bathtub in Danish elder care: a hermeneutic interview study. Nurs Health Sci 17(3):280-286

68. Abdi J, Al-Hindawi A, Ng T, Vizcaychipi MP (2018) Scoping review on the use of socially assistive robot technology in elderly care. BMJ Open 8(2):e018815. https://doi.org/10.1136/bmjop en-2017-018815

69. Holthe T, Halvorsrud L, Karterud D, Hoel K-A, Lund A (2018) Usability and acceptability of technology for community-dwelling older adults with mild cognitive impairment and dementia: a systematic literature review. Clin Interv Aging 13:863-886

70. van Wynsberghe A (2013) Designing robots for care: care centered value-sensitive design. Sci Eng Ethics 19(2):407-433

71. European Parliament (2017) Report with recommendations to the Commission on Civil Law Rules on Robotics (2015/2103/ INL). http://www.europarl.europa.eu/doceo/document/A-8-20170005_EN.html. Accessed 5 Nov 2019

72. Kim K-i, Gollamudi SS, Steinhubl S (2017) Digital technology to enable aging in place. Exp Gerontol 88:25-31

73. Bedaf S, Marti P, Amirabdollahian F, de Witte L (2018) A multiperspective evaluation of a service robot for seniors: the voice of different stakeholders. Disabil Rehabil Assist Technol 13(6):592599. https://doi.org/10.1080/17483107.2017.1358300

74. Saborowski M, Kollak I (2015) 'How do you care for technology?'-Care professionals' experiences with assistive technology in care of the elderly. Technol Forecast Soc Change 93:133-140

75. Kachouie R, Sedighadeli S, Khosla R, Chu M-T (2014) Socially assistive robots in elderly care: a mixed-method systematic literature review. Int J Hum Comput Interact 30(5):369-393

76. Šabanović S (2010) Robots in society, society in robots. Int J Soc Robot 2(4):439-450

77. Lee HR, Śabanović S, Chang WL., Hakken D, Nagata S, Piatt J, Bennett C (2017) Steps toward participatory design of social robots: mutual learning with older adults with depression. In: 2017 12th ACM/IEEE international conference on human-robot interaction, pp 244-253

78. Revenson TA, Griva K, Luszczynska A, Morrison V, Panagopoulou E, Vilchinsky N, Hagedoorn M (2016) Caregiving in the illness context. Palgrave Macmillan, Basingstoke. https://doi. org/10.1057/9781137558985.0009

79. Woods S, Walters M, Kheng Lee K, Dautenhahn K (2006) Comparing human robot interaction scenarios using live and video based methods: towards a novel methodological approach. In: 9th IEEE international workshop on advanced motion control

80. Polit DF, Beck CT (2010) Nursing research: Appraising evidence for nursing practice. Lippincott Williams \& Wilkins, Philadelphia

Publisher's Note Springer Nature remains neutral with regard to jurisdictional claims in published maps and institutional affiliations.
Rose-Marie Johansson-Pajala received her $\mathrm{PhD}$ in caring sciences in the School of Health, Care and Social Welfare at Mälardalen University, Sweden, where she currently is a Senior Lecturer in medical science. Her research interest is in elderly care, with a particular interest in welfare technology.

Kirsten Thommes is professor for Organizational Behavior at Paderborn University, Germany. In her research, she focuses on radical shifts in firms' institutional environment and co-creation and collaboration in teams. In her current research, she is especially interested in humanmachine interaction and collaboration at work.

Julia A. Hoppe is PhD student at the chair of Organizational Behavior at Paderborn University, Germany. Her research interest is in humanmachine interaction and in collaboration at work especially collaboration in teams.

Outi Tuisku received her M.Sc. degree in computer science in 2008 and her Ph.D. degree in interactive technology in 2014 from the University of Tampere, Finland. Currently she works as a post-doctoral researcher at the Lappeenranta-Lahti University of Technology LUT, Finland, where her work is connected to LUT research platform on Smart Services for Digitalisation (DIGI-USER).

Lea Hennala ( $\mathrm{PhD}$, Innovation systems), is a Senior Researcher at Lappeenranta-Lahti University of Technology LUT, School of Engineering Science, Finland. Her research areas include e.g. implementation and use of care robots in elderly care, user-involvement and co-creation of service innovations in both public and private sectors.

Satu Pekkarinen ( $\mathrm{PhD}$, Innovation systems), is a Senior Researcher in Lappeenranta-Lahti University of Technology LUT, School of Engineering Science, Finland. Her research interests are related to the relationships between technology, services and users, both from theoretical and practical viewpoints. Her research areas include e.g. implementation and use of care robots, and socio-technical transition in elderly care.

Helinä Melkas D.Sc. (Tech.), is Professor of Industrial Engineering and Management, especially Service Innovations at LappeenrantaLahti University of Technology LUT, School of Engineering Science, Finland. Her research focus is digitalisation, well-being technology, gerontechnology, robotics, service innovation, and user involvement.

Christine Gustafsson received her $\mathrm{PhD}$ in gerontological caring at Karolinska Institutet in Sweden. She is currently holding the position Associate Professor at Mälardalen University, Sweden at the School of Health, Care and Social Welfare. Her research interest is in elderly care and intellectual disability practice, with a particular interest in health and welfare technology. 